\title{
Causal Relationship between Monetary Policy and the Stock Market: a Bootstrap Rolling Window Approach
}

\author{
Khalid Khan
}

$\mathrm{PhD}$, Assistant Professor, School of Finance, Qilu University of Technology, Changqing, Jinan, Shandong, China.

\section{Wang Qingyang}

Droit et AES, Universite de Bretagne, Brest, France.

\section{Adnan Khurshid}

$\mathrm{PhD}$, Assistant Professor, Economic Department, University of Abbottabad, Pakistan.

\begin{abstract}
This study examines the causal relationship between the monetary policy and the stock price in Pakistan. We use bootstrap Granger full-sample causality test and sub-sample rolling window estimation test for the period of 1992:01 to 2015:06. The empirical result shows that there is a unidirectional causality from monetary policy to the stock price. However, considering the structural changes, we assess the parameter stability by using the full sample for short run relationship and find the short run instability for the full sample. This recommends that full-sample data cannot depend upon for the precise result. To address the structural changes issue, we propose rolling window approach is used to revisit the causal relationship between the two series and the result reports the bi-directional causal relationship between the monetary policy and the stock market. The relationship between the stock market and the money supply is not consistent, and the upward trend may cause serious policy implication on the stock market for future investment and profit.
\end{abstract}

Key words: Monetary policy, stock market, Rolling Window, Bootstrap, Time-Varying Causality. JEL Classification: E52, G12, C2.

(C) The Authors, 2017. This article is published with open access at ARMG Publishing.

\section{Introduction}

The relationship between the stock market and monetary policy has become an area of interest. The recent financial crisis has enhanced the importance to study the relationship between the monetary policy and stock market (Thorbecke, 1995). It is significant to evaluate the impact of the future course of action in the economy. Both are directly and indirectly sensitive towards the inflation, real output and interest rate (Ioannidis and Kontonikas, 2006). The monetary policy is a device to control the money supply and liquidity which have an ultimate goal of price stability; low unemployment and the stock market provide an opportunity to corporate sectors raise capital for business financing (Okpara 2010). Thus, the information of one side can predict the future action of another one. The changing pattern of economies should study to investigate the relationship (Gregoriou et.al. 2009; Abaenewe and Ndugbu 2012). The precise relationship between the monetary policy and the stock market gives a better understanding of the transmission mechanism. Several studies show stock market as one of the transmission mechanism of monetary policy, which interconnected to the economy and may have the impact on the consumer spending and the investment Goodhart and Hofmann, 2010). The monetary policy is a touchstone for investors and government authorities both have insight information to predict their future course of action (Mishkin, 1996). It should consider the stock market to prevent the substantial fluctuations in the prices. As according to the different economist, the stock market volatility has direct or indirect destabilizing effect on the monetary policy. The nature of relationships is necessary to examine as the price stability is the principal goal of the monetary policy, and a stock market is an important unit in the economy (Bernanke and Gertler, 1999).

The study contributes to the existing literature to revisit relationship of monetary policy and the stock market taking into account the significant changes occurs as a result of globalization and financial openness (Hassan and Javed, 2009). The dynamic relationship between the monetary policy and the stock market is significant in the context of the emerging country like Pakistan. Over the last two decades, Pakistan economy has confronted high inflation, high-interest rate and structural weakness which enhanced the importance of an effective monetary policy and sound capital market. Pakistan is an underdeveloped economy, and recently various reforms started to develop the capital market. The process of privatization, economic liberalization, and easing of regulations on operation of financial institutions has initiated to facilitate the development of the 
financial market in the country (Hussain and Mahmood, 1999). These reforms have to boost up the inflow of the foreign investment in the financial market which may make the stock market vulnerable to any fluctuations in the monetary policy. In 1997-98, Pakistan faced economic challenges and hit by the Asian financial and the economic sanctions imposed due to the atomic explosion. In the 2000s an average economic growth rate of 7 percent is achieved. The Karachi stock market among the best performing stock market in the emerging economies. The monetary policy may have an adverse implication for the equity market (Alam and Muzafar, 2014). In 2007-08 the global financial crisis and the internal economic instability in the shape of energy crisis, law and order situation, political instability, massive foreign debts have a significant impact on the economy. The domestic weak economic condition and the recent global financial crisis have enhanced the importance of the stock market and monetary policy relationship. These factors give encourages investigating the relationship between the stock market and the monetary policy in Pakistan.

\section{Literature review}

Fazal and Mahmood (1999) find both the long and short-term relationship between the money supply (M2) and the stock market return. Ahmad and Hussain (2007) find that the monetary policy causes the stock market in both long and short term. Maskay (2007) investigate the relationship between the stock market index and money supply and conclude the negative correlation. Caporale (2010) assess the contribution of the stock market moment in the money supply in the Germany, UK, US, result shows that the stock market plays a major role in the money demand. Bohl et al. (2008) analyze the European stock market response to the monetary policy, and the results indicate negative relations between the stock price and the monetary policy. Raymond (2009) reports negative relationship between the stock market index and the money supply. Okpara (2010) finds that the monetary policy has a negative impact on the stock market return in Nigeria. Qayyum and Anwar (2011) find significant the impact of monetary policy on the stock market in Pakistan. Mohamadpour et al. (2012) conclude the positive long term of monetary policy on the Kuala Lumpur Composite index. Mohamadpour et al. (2012) examine the link between the stock market and the monetary policy and find the long-term relationship. Mustafa et al. (2013) examine the relationship between the stock market and monetary policy and they conclude that stock market causes the monetary policy in the short term. Soureh et al. (2014) show the positive impact of the money volume on the stock market bubbles. Omidi (2015) indicates the positive impact of monetary policy on the stock market bubble in the Tehran stock exchange. Laopodis (2006) show no relationship between the monetary policy and the stock market. Kandir, (2008) and Ali et al. (2010); find no relationship between money supply and stock prices.

This study is conducted to find the relationship between the monetary policy and the stock market. There is a dearth of research related to the Pakistan in the area of monetary policy and the stock price. As from the review of previous literature, the causality between the two series may suffer from the misleading result in the presence of structural changes in the full sample time series data. (Balcilar et al., 2010). The economic sanctions, the Asian financial crisis, weak internal economic condition, global financial crisis and the recent wave of terrorism in Pakistan cause structural changes in the economy. These structural changes led to show instability between the monetary policy and the stock market. To overcome weaknesses of the conventional methods, we propose a new technique of determining the causality between the monetary policy and the stock market in Pakistan, the bootstrap Granger full sample causality test and the sub-sample relationship between the rolling window estimation. This method has the advantage that it finds the full sample and sub-sample relationship and finds the structural changes over these time periods. This study takes into the consideration the full sample causality as well as the sub-sample by using the rolling sub-sample with fixed window size to test the causality causal link between the monetary policy and the stock market. The rolling window approach captures the structural changes. The results show the bidirectional relationship between the monetary policy and the stock market exist in several sub- samples. The relationship between the money supply and the stock price is twoway at various sub-samples. The money supply has both positive and negative impact on the stock price and vice versa.

This study has the following sections. Section 2 is literature review. Section 3 presents the methodology, section 4 consists of data, section 5 explains the empirical result and section 6 present conclusions.

\section{Methodology}

The objective of this paper to find the causal relationship between the stock market and the money supply (M2). The standard Granger causality test is defined as, whether the previous information of a variable improves the forecasting of another variable. In this sense, if a variable does not Granger cause the other 
variables; the available prior information does not result in the other variables. The Likelihood ratio, and Wald, Lagrange multiplier (LM) test statistic, for testing the Granger causality. The standard Granger causality has the disadvantage of non-asymptotic properties if the variables considered are co-integrated or integrated and with small size and distinct bias and spurious regression. The issue of the integration can be overcome by employing the Toda and Yamamoto (1995), which has the advantage to produce the valid asymptotic critical values, irrespective of the level of integration or co-integration. Shukur and Mantolos (1997a) examine the power and size properties of the modified Wald test by employing the Monte Carlo Simulation and they conclude does not correct size in small- and medium-sized samples. However, the power and size are improved by using the residual based bootstrap $(R B)$ method (Shukur and Mantalos (1997b). A number of Monte Carlo Simulation studies have established that RB method performance is better than the standard asymptotic test (Mantalos and Shukur, 1998; Shukur and Mantalos, 2000; Mantalos, 2000; Hacker and Hatemi-J, 2006; Balcilar et al., 2010). In particular, Shukur and Mantalos (2000) verify that small sample modified $L R$ tests show comparatively better power and size properties. Their results show that in the absence of co-integration, all standardized tests that do not use the $R B$ method perform inadequately, particularly in small samples. We employ the bootstrapping Granger causality test to avoid the small size issue. The study uses residual bootstrap $(R B)$ methods used Balcilar et.al. (1995), which produce the robust critical values

To show the RB-based modified-LR causality test, the bivariate VAR ( $p$ ) process is considered as follows:

$$
\left[\begin{array}{l}
S T_{1 t} \\
M 2_{2 t}
\end{array}\right]=\left[\begin{array}{l}
\phi_{10} \\
\phi_{20}
\end{array}\right]+\left[\begin{array}{l}
\phi_{11}(L) \phi_{12}(L) \\
\phi_{21}(L) \phi_{22}(L)
\end{array}\right]\left[\begin{array}{l}
S T_{1 t} \\
M 2_{2 t}
\end{array}\right]+\left[\begin{array}{l}
\varepsilon_{1 t} \\
\varepsilon_{2 t}
\end{array}\right] t=1,2, \ldots \ldots . T
$$

where $\varepsilon_{t}=\left(\varepsilon_{1 t}, \varepsilon_{2 t}\right)^{\prime}$ is a zero mean, independent, white noise process with non-singular covariance matrix $\sum$. The optimal lag length $p$ is determined by the Schwarz Information Criteria (SIC) in this study. ST and M2 indicate stock price and money supply respectively. $\phi_{i j}(L)=\sum_{k=1}^{p+1} \phi_{i j, k} L^{k}, i, j=1,2$ and $L$ is the lag operator defined as $L^{k} x_{t}=x_{t-k}$.

Based on Equation (1) the null hypothesis that money supply does not Granger causes the stock price is tested by imposing the restriction $\phi_{12, k}=0$ for $k=1,2, \ldots ., p$. Similarly, the null hypothesis that stock price does not Granger causes money policy is tested by imposing the constraint, $\phi_{21, k}=0$ for $k=1,2, \ldots . ., p$. As discussed, the full-sample causality tests in this paper rely on $R B$-based $p$-values and modified- $L R$ statistics. If the first null hypothesis $\phi_{12, k}=0$ for $k=1,2, \ldots \ldots, p$ is rejected, there is a significant causality running from money policy to stock market. This means monetary policy can predict movements in the stock market. Similarly, if the second null hypothesis $\phi_{21, k}=0$ for $k=1,2, \ldots . ., p$ is rejected, stock market causes the monetary policy, the stock market has predictive power. The augmented Dickey Fuller (1981), Philip and Perron (1988) and Ng and Perron (2001) are used to investigate the stationary. The lag length is selected by employing the Akiake Information Criteria (AIC).

\section{Parameter stability test}

The time series analysis assumes that the underlying parameters is stable over time, but sometimes the assumption does not hold because of structural changes. The outcome from full sample causality test would become misspecified, and hence, the causal associations between the series would show variability. (Balcilar and Ozdemir, 2013). Granger (1996) stresses the issue of parameter non-constancy as one of the most challenging issues faced by recent empirical studies. The presence of the structural break in the data is detected by parameter stability test.

Andrews (1993) and Andrews and Ploberger (1994) addressed the short run parameter instability by using the Sup- $F$, Exp-F, Mean- $F$ test. We apply $L_{c}$ test (Nyblom, 1989; Hansen, 1992) to test for all parameters in the overall VAR system. However, the underlying variables are cointegrated in levels; the VAR model in the first difference is misleading unless it is corrected with error correction. The rolling estimation technique produces various parameter estimates which are more or less alike for the system to exhibit the stability. If a time series display parameter estimate that different from other is likely to suffer from instability and result of estimation is unreliable. Therefore, we employ rolling-window Granger causality test which detects the structural change and may give different causality result over the rolling sub-sample of data. 
The Sup-F, Mean-F and Exp-F are calculated from the sequence of $L R$ statistics, which examined the null hypothesis of parameter constancy against one-time structural change at each possible point of time in the full sample. The $p$-values and the critical values by employing the bootstrap method. According to the Andrew (1993), fifteen percent of both sides are trimmed, and the sample is reduced to the $[0.15,0.85]$ which the relevant sample to be tested for parameter stability. With respect $L_{c}$ test they are computed for the equation as well as the VAR system separately by using the FM-OLS estimators.

\section{Sub sample Rolling window causality test}

The structural changes are a challenge in the time series study. The various technique is used to address these structural breaks, i.e. dummy variables and sample splitting. The pre- test bias arises due to these methods. A rolling window sub-sample Granger causality is used to avoid the parameter constancy and pre-test bias (Balcilar et al., 2010). There are two significant factors for employing the rolling estimations first; the causal relationship between variables can change over time. Second, rolling estimation can detect instability across different sub-samples due to structural change, and the rolling-window estimation captures this process. According to Balcilar et al. (2010), rolling window process is based on the fixed-size sub-sample. On the basis of this statement the fixed-size rolling window with given observation, the full sample is converted to a sequence of T-1 sub-sample that is, $\tau-1+1, \tau-1$, T for $\tau=1,1+1, \ldots, T$. Now this RB-based modified- $L R$ causality test is alternative to single causality test for full sample to test each sub-sample. Possible changes in the causal links between monetary policy and stock market are intuitively identified by calculating the bootstrap p-values of observed $L R$-statistics rolling through T-1 sub-samples. The impact of monetary policy on the stock market is defined as the average of the entire bootstrap estimates derived from the formula, with representing the number of bootstrap repetitions; similarly, the impact of the stock market on monetary policy is obtained from the formula. Both and are bootstrap estimates from the VAR models in Equation (1) The 90-percent confidence intervals are also computed, for which the lower and upper limits equal the 5th and 95th quantiles of each of the $\varnothing_{21, \mathrm{k}}$ and $\varnothing_{12, \mathrm{k}}$, respectively (Balcilar et al., 2010).

The rolling window estimation should meet the criteria of the accuracy of parameters and representativeness of the model which depends upon the window size.

The window size is the precision of estimates, and it controls the number of observations. A small window size improves the repressiveness but reduces the accuracy. On the other, a large window size may improve the precision of estimates but may reduce the representativeness in the presence of heterogeneity. Consequently, we must select a suitable window size to balance the trade-off between representativeness and accuracy. A large window size is needed to ensure the precision of parameter estimates, but a window size that is too large may increase the risk of including some of these multiple shifts in the window sample claims for a smaller window size. As for the issue of inaccurate estimates as a result of the selected small window size, it can be addressed by the bootstrap technique employed in the rolling estimation for better precision.

According to (Balcilar et al., 2010 there is no specific procedure to select the window size in rolling estimations. Pesaran and Timmerman (2005) they report that under the structural changes window size is depend on persistence and size of the breaks and select the window size according to the square root mean square error. On the other hand, the Monte Carlo simulation under the frequent breaks recommends the minimum limit of the window size of 20. In views of the above two conflicting requirements, we select the 30month window size. A large window size improves the precision of parameter estimates, but at the same time, the large window size may increase the risk of including some of these multiple shits in the window size sample claims for a smaller window. The bootstrap technique is used to overcome the issue of inaccurate estimation which arises as a result of the small window

\section{Data}

This paper uses the monthly data from 1992:01 to 2015:06. The monetary policy is represented by the money supply (M2), and the stock market is represented by Karachi Stock Market Index (KSE-100). The money supply data is obtained from the economic survey of Pakistan and the State Bank of Pakistan annual reports. The KSE-100 index data is collected from the Karachi Stock Exchange website and economic survey of Pakistan. First, all the data are transformed to the natural logarithm to correct for potential heteroscedasticity and the dimensional difference between series. The sample periods have experienced some unfavourable economic events on both the external and internal front. The period witnessed an unprecedented boom in the stock market. The Asian financial crisis of 1997 and the global financial crisis in 2008 is the most crucial one. On the internal fronts, nuclear test in 1998 faced the economic sanction which has an adverse impact on the 
stock market. In 1998 the Karachi Stock Index (KSE-100) decline due to the south East Asian financial crisis, the imposition of an economic sanction on account of nuclear test. In the first half of the 2000 s the average economic growth rate was more than 7 percent, cheap credit was available on the market. In the same periods, the stock index and the money supply increased in the same direction. In April 2008, the KSE-100 index crossed the 15,000 points in its stock exchange history. The global financial crisis and the internal weak economic condition cause the stock market to decline the equity market sharply, the KSE-100 is fallen by 62 percent. To control the further decline a "floor "was fixed at 9144 points. A tight monetary policy adopted to cope up the financial crisis implication. The overall moment of the stock market and money supply by the state bank are in the same directions. In general, the stock market and the money supply have a weak relationship which makes the relationship more complicated.

The first step is to detect to the stationary of the series. We use the Augmented Dickey Fuller (1991), Philips and Perron (1998) and KPSS test proposed by Kwiatowski et al. (1992). The test shows that both the M2 and the ST are not stationary in their levels but after differencing, both the series become stationary, which is integrated of order one 1(1). In the next step, we test the full sample causal relationship between the two variables using the VAR model. The lag structure is calculated for the bivariate VAR model. The optimal lag length is calculated by the Schwarz information Criteria (SIC), select one as the optimal lag length.

Table1. Unit root test of money supply and the stock price

\begin{tabular}{|l|c|c|c|c|c|c|}
\hline \multirow{2}{*}{ Variables } & \multicolumn{3}{|c|}{ Level } & \multicolumn{3}{c|}{ Difference } \\
\cline { 2 - 7 } & ADF & PP & KPSS & ADF & PP & KPSS \\
\hline M2 & $0.241(13)$ & $0.35(7)$ & $1.907(14)^{* * *}$ & $3.141(12)^{* * *}$ & $-14.783(4)^{* * *}$ & $0.152(7)$ \\
\hline SM & $0.244(0)$ & $0.164(6)$ & $1.774(14)^{* * *}$ & $-16.059(0)^{* *}$ & $-16.076(6)^{* * *}$ & $0.169(6)$ \\
\hline
\end{tabular}

Note: $* * *$ and $* *$ indicate significance at the $1 \%$ and $5 \%$ levels, respectively. The numbers in parenthesis indicate the lag orders selected based on the recursive $t$-statistic, as suggested by Perron (1989). The numbers in the brackets indicate the truncation for the Bartlett Kernel, as suggested by the Newey-West test (1987).

The LR test uses the $p$-values obtained 10000 Bootstrap approximation replications. By means of the RB based modified- $L R$ causality tests, the full-sample causality results are reported in Table $\mathbf{2}$. The null hypothesis for the full sample Granger causality test that M2 does not Granger causes the ST. The results of the Bootstrap LR test conclude the unidirectional causality running from M2 to ST. These results are consistent with the existing literature (Hussain and Mahmood, 1999; Ahmad and Hussain, 2006).

To test the reliability and validity of the full sample Granger causality results, it needs to investigate the parameter stability of the coefficient of our estimated VAR model. This type of parameter stability test is required to complement the full sample Granger causality test, as if the estimated parameter is stable over the full-sample, we can conclude that our results are valid. On the other hand, if the parameter shows the parameter instability then the result is unreliable for full sample Granger causality results thus need to examine the specific periods in the sample where the instability occurs.

Table 2: Full-Sample Granger Causality Tests

\begin{tabular}{|c|c|c|c|c|}
\hline Test & \multicolumn{2}{|c|}{ Ho: M2 does not Granger cause ST $^{2}$ Ho: ST does not Granger cause M2 } \\
\hline \multirow{2}{*}{ Bootstrap LR Test } & Statistics & $\boldsymbol{p}$-values & Statistics & $\boldsymbol{p}$-values \\
\cline { 2 - 5 } & $5.626^{* *}$ & 0.022 & 5.569 & 0.83 \\
\hline
\end{tabular}

Note: ** indicates significance at the $5 \%$ level.

However, there is a default assumption in previous literature that in time series structural changes do not exist and there is only a single causal relationship for the full-sample periods (Balcilar et al., 2013). In the presence of structural changes, the parameter in the VAR models using full-sample will shift with time, and the result is unstable. Therefore, the full-sample causality test with the assumption of parameter constancy and a single causal relationship for the full-sample results are unreliable and invalid (Zeileis et al., 2005). The above factors may cause the conflicting results; it is, therefore, imperative to investigate parameter constancy and the possible causes of such deviation in the parameter. The Sup-F, Mean-F, Exp-F test is used for short term stability. The Sup-F, Mean-F, Exp- $F$ test the null hypothesis of parameter constancy against the parameter non-constancy. The Sup-F test is used to detect that whether the regime shift occurred or not, whereas the Exp$F$, Mean-F, investigates the model stability over time (Balcilar et al., 2010). The $L c$ test of Nyblom (1989) and Hansen (1992) is also used to test for all parameters in the overall VAR system. 
In Table 3, the results of the test for both series along with the related $p$-values are described. These $p$-values are attained from the Bootstrap approximation to the null distribution of the test statistics, constructed using Monte Carlo Simulation using 2,000 samples generated from the VAR model with a constant parameter. The results of the Sup-F test under the null hypothesis of one-time sharp shift are obtained, reported in the table. The result exhibits that parameter instability in the monetary policy equations exists, as the null hypothesis is rejected at the 1 percent level of significance. On the other hand, the stock market equation fails to reject the null hypothesis by the Exp-F test in the stock market index. The result of the Sup-F exhibits the existence of one-time sharp shift in the series. The Mean-F and Exp-F test also can not reject the null hypothesis for the stock market equation. The entire three tests, the Mean-F, Exp-F, Sup- F test, are shows that there is a parameter instability in the stock market equations since the null hypothesis is rejected at one 1 percent level of significance. It is evident from the result that there is short term parameter instability exist in the monetary policy equations. However the stock market equations have a stable parameter. The results for the overall VAR model for the Sup-F, Mean-F, Exp-F, shows the parameter stability since the null hypothesis for all the three tests are fails to reject. The result exhibits that it does not evolve gradually. The $L c$. test is used to shows the long-term parameter stability of parameter of the model. The results for the $L c$ detect that parameter follows the random walk process proposed by Gardner (1969), evidence of the parameter constancy in the overall VAR models estimated. As according to the results reported in Table 3, it is concluded that our model has unstable parameter over the sample period implying that the full-sample results are unreliable and invalid.

As the above test detect the existence of structural shift in the model, so any statistical inference based on this assumption is likely to be invalid. The dynamic relationship between the monetary policy and the stock market shows instability across the different sub-sample in the models, and this gives the sufficient impetus to use the rolling-window technique to assess the VAR model to capture these structural breaks. The rolling- window approach has the advantage to detect the dynamic causal link between the two equations more precisely in the presences of structural breaks in the different sub-samples (Balcilar et al., 2010). The Rolling estimators, also commonly known window size, selected on the basis of probable accuracy and precision of parameter estimators. We select the window size 30 window periods. According to Balcilar et al. (2013), the choice of window size is a significant feature to study, as it concludes the number of rolling estimates. The greater the window size, the more the precision of estimates though in the existences of heterogeneity there may be less representativeness of parameters. The smaller fixed window size.

Table 3. Parameter Stability Tests

\begin{tabular}{|l|c|c|c|c|c|c|}
\hline \multicolumn{2}{|c|}{ M2 Equation } & \multicolumn{3}{c|}{ ST Equation } & \multicolumn{2}{c|}{ VAR Equation } \\
\hline & Statistics & $\begin{array}{c}\text { Bootstrap } p \\
\text { values }\end{array}$ & Statistics & $\begin{array}{c}\text { Bootstrap } \mathrm{p} \\
\text { values }\end{array}$ & $\begin{array}{c}\text { Statistics } \\
\text { Bootstrap p } \\
\text { values }\end{array}$ \\
\hline Sup $-F$ & $80.689^{* * *}$ & 0.000 & 7.486 & 0.486 & $23.297^{* *}$ & 0.015 \\
\hline Mean-F $F$ Exp-F & $25.719^{* * *}$ & 0.000 & 2.918 & 0.461 & $10.011^{*}$ & 0.056 \\
\hline$L_{c}{ }^{b}$ & 36.639 & 1.000 & $1.875^{* *}$ & 0.422 & $7.130^{* *}$ & 0.043 \\
\hline
\end{tabular}

Notes: We calculate $p$-values using 2,000 bootstrap repetitions.

${ }^{*}{ }^{* *}$ and ${ }^{* * *}$ denote significance at 10,5 and 1 percent, respectively.

${ }^{\mathrm{b}}$ Hansen-Nyblom parameter stability test for all parameters in the VAR jointly

In Figure 1 below the the rolling estimates for each subsample are reported. It begins 30 months trimming from the beginning of the full sample, i.e. 1994: 06 to 2015:06. Panel (a) and (b) of Figure reports the bootstrap $p$-values of the rolling test statistics testing the null hypothesis; monetary policy has no impact on the stock market and the magnitude of effect monetary policy on the stock market. In the Figure 1 panel (a) the monetary policy does not Granger cause the stock market is rejected at 10 percent significant level in the several sub-sample, including 1997:08-2004:04,2008:09,2011:05,2011:11,2013:02-2013:09, 2013:102014:14. Theses sub-sample the monetary policy has an impact on the stock market. The panel (b) reports the bootstrap estimates of the rolling window coefficient to test the null hypothesis that monetary policy does not Granger cause the stock market and it is evident that in the sub-sample periods of 1997:08, the monetary policy has a negative impact on the stock market, whereas in the sub-sample of 2004:04, 2008; 09, 2011:05, 2011:11, 2013:02 to 2013:09 2013:10 to 2014:04 has a positive predictive power for stock market. 1997:08 to 2004:04, the monetary policy has a negative predictive power of the stock market. In the sub-sample, the money supply increased, and the central bank pursues the tight monetary policy. In the periods of 2004:04,2008;09,2011:05,2011:11,2013:02 to 2013:09 2013:10 to 2014:04 has a positive influence on stock market. In this specific period of time, as the money 


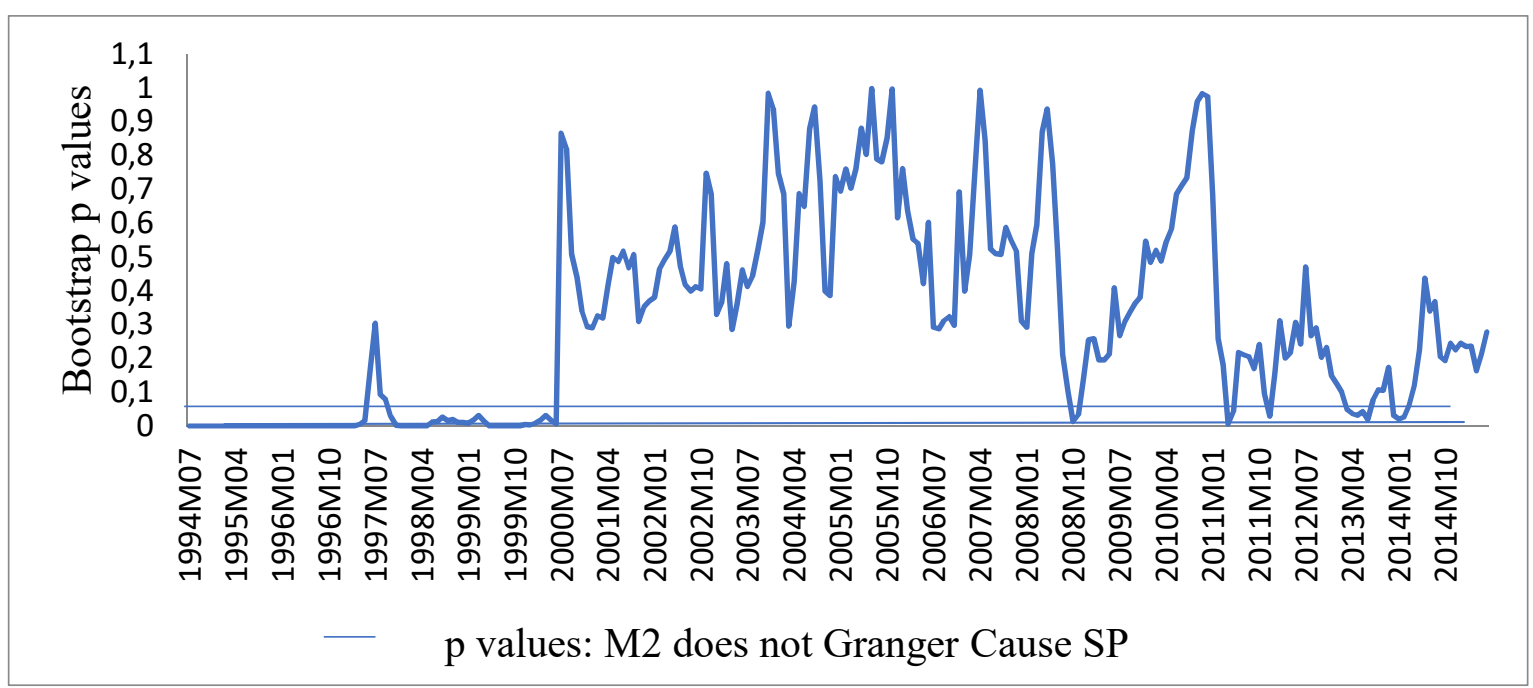

Fig. 1. Panel (a) Bootstrap $p$-value of rolling test statistic testing the null that M2 does not Granger cause ST

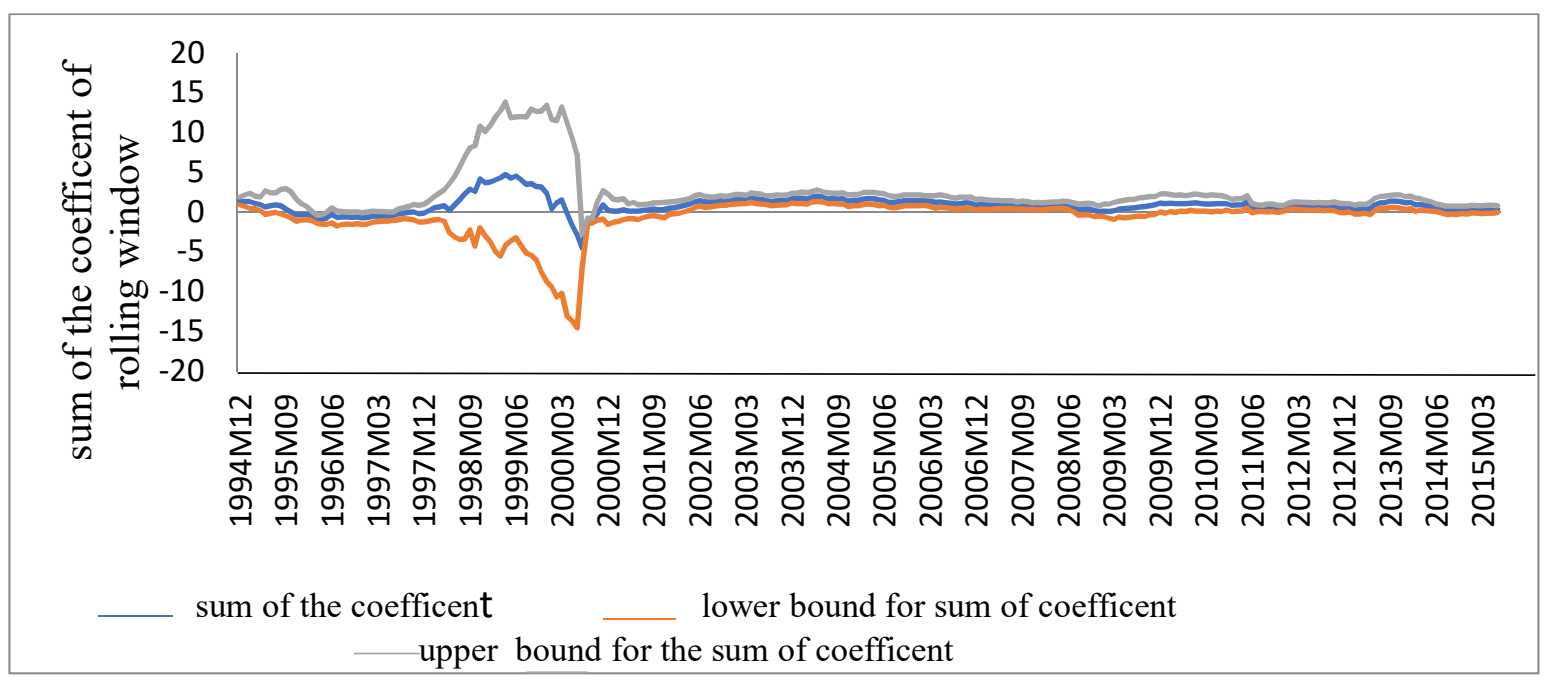

Fig. 1 panel (b). Bootstrap estimates of the sum of the rolling window coefficients for the impact of M2 on ST

supply witnessed an upward trend and at the same time, stock market has performed well. The money supply increases from 2486.6 billion rupees to $9,482,136$, million. The upward trend in the money supply may increase the future expectation about an economy. In 2008:09 the money supply (M2) deteriorates due to the external account position and the tight monetary policy by the State Bank of Pakistan (SBP), which left the money market dry, contraction of the money supply. In this period, the growth in the money supply (M2) was declined by $4.59 \%$ in the corresponding to the last years. The money supply decreased to Rs 215.0 billion from Rs 227.1 billion. The sharp decline is consistent with expected fiscal and external current account deficits, which is projected to be 8 percent. In sum, the result from the bootstrap sub-sample period's estimations shows both negative and positive effects of money supply (M2) on the stock price and in the remaining sub-sample periods it has an insignificant impact.

In the Figure 2 panel (a) exhibits the bootstrap p-values of the rolling test statistics to assess the null hypothesis that stock price does not Granger cause the money supply, and also examining the magnitude of the impact of stock price on the money supply respectively. The figure reports the sub-sample periods where the null hypothesis that stock price index does not Granger causes the money supply reject the null hypothesis at a 10 percent significance level, including 1994:04, 1996, 2002:02 to 2003:08, 2005:06 to 2006:05 2007:07, 2007:11, 2007:12, 2009: 12, 2010:12, 2011:04, 2011:12 to 2012:06, 2013:2014:03

The Figure 3 panel (b) shows the magnitude of impact of stock price index on the money supply and the bootstrap estimates of the sum of rolling window coefficient testing the null hypothesis stock market does not Granger cause the monetary policy and shows that from 1994:04, 1996:06,2002:02 to 2003:08 has a negative impact on the monetary policy and the sub-sample periods from 2005:06 to 2006:05, 2007:07, 2007:11, 
2007:12, 2009:12, 2010:12, 2011:04, 2011:12 to 2012:06, 2013:2014:03 has a positive effect on the monetary policy. The impressive growth of the stock market in 2004; rising from 3403 to 5430 points; an increase of 59.6 percent. The aggregate market capitalization also increased by 92.4 percent in the corresponding periods. In the specifics sub-sample, the market has more money available, improvement in the country economics condition, declining rate of alternative investment, stability in the exchange rate, a massive amount of liquidity in the market. It is evident from the Figure 3 and 4 that stock price has both negative and positive influence the money supply. In this period the economic condition improved. In sum, the study shows that the money supply and the stock price have both positive and negative bi-directional causality. In Pakistan, the stock market and the monetary policy has an inconsistent relationship. In the sample periods, the monetary policy and the stock market have both positive and negative bi-directional link (Seong, 2013).

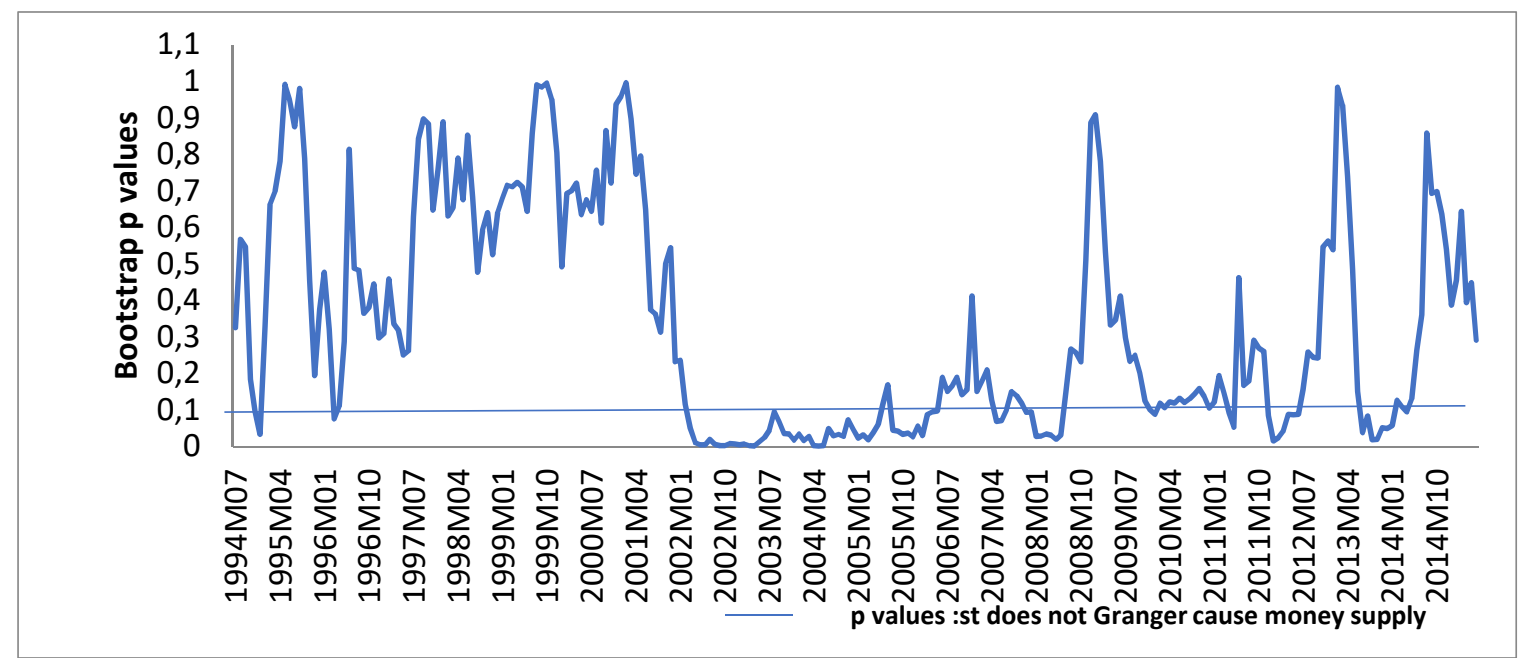

Fig. 2 panels (a). Bootstrap p-value of rolling test statistic testing the null that ST does not Granger cause M2

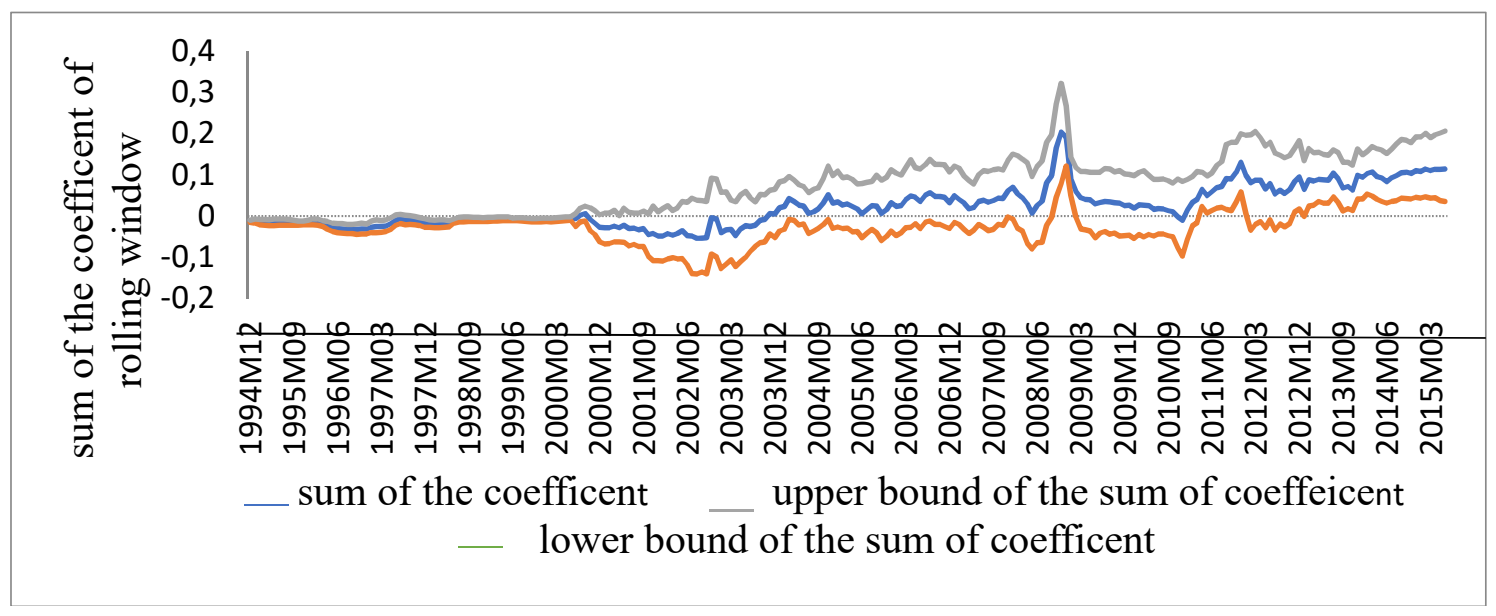

Fig. 2. panel(b) Bootstrap estimates of the sum of the rolling window coefficients for the impact of ST on M2

sample periods. In the early 1990s started the structural reforms in the financial sectors but since 2000 these reforms were pursued vigorously to achieve the economic stability and to compete for the global economic events. In 1998-1999 the economy was severely hampered due to economic sanctions and the Asian financial recession. The prevailed uncertainty shaken the investors' confidence in the market the demand for credit and economic activity declined. The Karachi stock index witness downturn in the same periods. State bank of Pakistan started a prudent monetary management with tight fiscal policy, and money supply increased in the market, government borrowing from banks, statutory liquidity ratio $(S L R)$, and the repo rate was sample periods. In the early 1990s started the structural reforms in the financial sectors but since 2000 these reforms were pursued vigorously to achieve the economic stability and to compete for the global economic events. In 1998-1999 the economy was severely hampered due to economic sanctions and the Asian financial recession. The prevailed uncertainty shaken the investors' confidence in the market the demand for credit and economic activity declined. The Karachi stock index witness downturn in the same periods. State bank of Pakistan started a prudent monetary management with tight fiscal policy, and money supply increased in the market, government borrowing from banks, statutory liquidity ratio $(S L R)$, and the repo rate was declined. The tense 
global business environment caused by $9 / 11$ events had an impact on the stock market and monetary policy. The state bank of Pakistan pursued a tight monetary policy to manage the precarious situation. The global financial crisis and the unstable internal economic and political condition in the fiscal year 2008-2009 damaged Karachi Stock Index (KSE-100). The volatile economic situation along the structural issues put the monetary management under pressure which further aggravated. The state bank revisits their monetary policy from expansionary to tight policy. The monetary policy and the stock market are two essential ingredients of an economy, and both are interrelated to each other. The economic events occurred at both domestic and global level has to impact on the relationship between the stock market and the monetary policy. The results suggest the policy implication; First, in the monetary policy formulation and execution, the stock market should take into account. Second, switching between various monetary policy stance formulated by State Bank of Pakistan would increase the risk premium for the stock investor.

\section{Conclusion}

The study is conducted aiming to examine the causal relationship between the monetary policy and the stock market. The study use the full-sample Granger Causality test and sub-rolling estimation. The rolling window estimation has the advantage that it captures the structural breaks which occurs over the periods. The results from the full sample Granger causality test show that the monetary policy predicts the stock market whereas the stock market does not Granger cause the monetary policy. The sub-sample parameter stability test show that in short runs, relationship between the monetary policy and the stock market is unstable. We use the bootstrap rolling window method to detect the sub-sample causality between the monetary policy and the stock price and the result shows the causal link between the two equations at the specific sub-sample. Our result in the sub-sample shows the bi-directional Granger causality between the monetary policy and stock price. The result shows both the positive and negative relationship between the monetary policy and the stock price. However, both stock price and money supply shows an upward trend, but our results show a weak relationship. The instability is observed in the causal link between the stock market and the monetary policy due to economic transition and the structural changes. The relationship between the money supply and the stock price has some implication for the economy. First, in the monetary policy formulation and execution, the stock market should take into account. Second, switching between various monetary policy stance formulated by State Bank of Pakistan would increase the risk premium for stock investors. The investor would perceive the tight monetary policy an indication of diminishing economic activity in the future.

\section{References}

1. Alatiqi, S. Fazel, S. (2008). Can Money Supply Predict Stock Prices? Journal for Economic Educators, 8, 54-59.

2. Ali, I. Rehman, K.U. Yilmaz, A.K. Khan, M.A. Afzal, H. (2010). Causal Relationship between Macroeconomic Indicators and Stock Exchange Prices in Pakistan, African Journal of Business Management 4, 312319.

3. Andrews, D. W. K. (1993). Tests for parameter instability and structural change with unknown change point. Econometrica, 61, 821-856.

4. Alam, S. Dawood, M. (2014). Movement analysis of Karachi stock exchange (1993 - 2012). European Scientific Journal, 10(19), 38-42.

5. Ahmad, N. Husain, F. (2006). The relation between stock prices and money supply in Pakistan: an investigation, Journal of Independent Studies and Research, 5, 2,30-45

6. Andrews, D.W.K. Ploberger, W. (1994). Optimal tests when a nuisance parameter is present only under the alternative, Econometrica, 62, 1383-1414.

7. Abaenewe, Z. C. Ndugbu, M. O. (2013). Analysis of the Effect of Monetary Policy Development on Equity Prices in Nigeria. West African Journal of Industrial and Academic Research, 5(1), 140-155.

8. Bernanke, Ben S. Mark Gertler, 1999, Monetary policy and asset price volatility. Federal Reserve Bank of Kansas City Economic Review 84, 17-5.1

9. Balcilar, M. Ozdemir, Z. A. Arslanturk, Y. (2010). Economic growth and energy consumption causal nexus viewed through a bootstrap rolling window. Energy Economics, 32, 1398-1410.

10. Balcilar, M. Ozdemir, Z.A. (2013). The export-output growth nexus in Japan bootstrap rolling window approach. Empirical Economics, 44, 639-660.

11. Bohl, M. T. Siklos, P. L. Sondermann, D. (2008). European Stock Markets and the Ecb's Monetary Policy Surprises. International Finance, 11, 117-130.

12. Bouakez, H. Essid, B, Normandin, M. (2013). Stock returns and monetary policy: Are there any ties? Journal of Macroeconomics, 36, 33-50. 
13. Chatziantoniou, I. Duffy, D. Filis, G. (2013). Stock market response to monetary and fiscal policy shocks: Multi-country evidence. Economic Modelling, 30, 754-769.

14. Cheung, Y. Ng, L. K. (1998). International Evidence on Stock Market and Aggregate Economic Activity, Journal of Empirical Finance, 5, 281-296.

15. Caporale, GM. Soliman, A.M. (2010). Stock prices and monetary policy: An impulse response analysis. http://bura.brunel.ac.uk/bitstream/2438/5043/1/1022\%5B1\%5D.pdf

16. Chen, N. (1991). Financial Investment Opportunities and the Macroeconomy, Journal of Finance, 46, 529554.

17. De Grauwe, P. (2008). Stock prices and monetary policy (No. 304). CEPS.

18. Goodhart, C. Hofmann, B. (2000). Asset prices and the conduct of monetary policy. In Sveriges Riksbank and Stockholm School of Economics conference on Asset Markets and Monetary Policy, Stockholm.

19. Gjerde, O. Saettem, F. (1999). Causal Relations among Stock Returns and Macroeconomic Variables in a Small Open Economy. Journal of International Financial Markets, Institutions and Money, 9, 61-74.

20. Gregoriou, A. Kontonikas, A. MacDonald, R. Montagnoli, A. (2009). Monetary policy shocks and stock returns: evidence from the British market. Financial Markets and Portfolio Management, 23 401-410.

21. Granger, C. W. J. (1996). Can we improve the perceived quality of economic forecasts? Journal of Applied Econometrics, 11, 455-73.

22. Hansen, B. E. (1992). Tests for parameter instability in regressions with $I(1)$ processes. Journal of Business and Economic Statistics, 10, 321-336.

23. Hasan, A. Javed, M. T. (2009). An empirical investigation of the causal relationship among monetary variables and equity market returns. The Lahore Journal of Economics, 14,115-137.

24. Hacker, R. S. Hatemi-J, A. (2006). Tests for causality between integrated variables based on asymptotic and bootstrap distributions: theory and application. Applied Economics, 38, 1489-1500.

25. Husain, F. T. Mahmood, T. Azid. (1999). Monetary Expansion and Stock Returns in Pakistan [with Comments], The Pakistan Development Review, 38,769-776.

26. Kandir, S.Y. (2008). Macroeconomic Variables, Firm Characteristics and Stock Returns: Evidence from Turkey. International research journal of finance and economics, 16, 35-45.

27. Kwiatkowski, D. Phillips, P. Schmidt, P. Shin, Y. (1992). Testing the null hypothesis of stationary against the alternative of a unit root: how sure are we that economic time series have a unit root? Journal of Econometrics, 54, 159-178.

28. Ioannidis, C. Kontonikas, A. (2006). Monetary policy and the stock market:Some international evidence. Department of Economics, University of Glasgow.

29. Lu, G. M. K. Metin IV, Argac, (2001). Is there a Long Run Relationship between Stock Returns and Monetary Variables: Evidence from an Emerging Market, Applied Financial Economics, 11, 641-649.

30. Laopodis, N. T. (2006). Dynamic Interactions among the Stock Market, Federal Funds Rate, Inflation, and Economic Activity, The financial Review, 41(4), 513-545.

31. Mantalos, P. Shukur, G. (1998). Size and power of the error correction model cointegration test: a bootstrap approach. Oxford Bulletin of Economics and Statistics, 60, 249-255.

32. Mantalos, P. (2000). A graphical investigation of the size and power of the granger-causality tests in integrated-cointegrated VAR systems. Studies in Non-Linear Dynamics and Econometrics, 4, 17-33.

33. Mustafa, K. Ahmed, R. Siddiqui, A. A. (2013). Money Supply and Equity Price Movements in Pakistan. European Journal of Business and Management, 5, 146-157

34. Nguyen, C. V. (2014). Pakistani Broad Money Supply and Stock Price Behavior, Stud, journal of Asian development, $3,77-89$.

35. Mukherjee, T. K. Naka. A. (1995). Dynamic Relations between Macroeconomic Variables and the Japanese Stock Market: An Application of a Vector Error Correction Model, Journal of Financial Research, $18,223-237$.

36. Maskay, B. (2007). Analyzing the Effect of Change in Money Supply on Stock Prices, The Park Place Economist, 15,72-79.

37. Mishkin, F. S. (1996). The channel of monetary Transmission: lesson for Monetary Policy, Banque De France Bulletin Digest No.27 :33-44.

38. Mohamadpour, B. Behravan, N. Espahbodi, S. Karimi, R. (2012). An Empirical Study of Relationship between Monetary Policy and Stock Market Performance in Malaysia, Australian Journal of Basic and Applied Sciences, 6(12), 142-148.

39. Shukur, G. Mantalos, P. (2000). A simple investigation of the Granger-causality test in integratedcointegrated VAR Systems. Journal of Applied Statistics, 27, 1021-1031; 
40. Nyblom, J. (1989). Testing for the constancy of parameters over time. Journal of the American Statistical Association, 84, 223-230.

41. Nawaz, A. Husain, F. (2006). The relation between stock prices and money supply in Pakistan: an investigation. Journal of Independent Studies and Research (JISR), 5, 30-32

42. Okpara, G. C. (2010). Monetary policy and stock market returns: Evidence from Nigeria. Journal of Economics, 1, 13-21.

43. Qayyum, A. Anwar, S. (2011). Impact of Monetary Policy on the Volatility of Stock Market in Pakistan. International Journal of Business and Social Science, 2(11), 18-24.

44. Pesaran, M. H. Timmermann, A. (2005). Small sample properties of forecasts from autoregressive models under structural breaks. Journal of Econometrics, 129, 183-217.

45. Praptiningsih, M. (2010). The impact of monetary policy toward indonesian stock market under inflation targeting regime.Lex ET Scientia International Journal (LESIJ), 17, 240-2

46. Stoica, O. D.-E. Diaconașu. (2012). Monetary Policy and Stock Markets Evidence from Eu Countries, Communications of the IBIMA, 2012, 1-11.

47. Shaoping, C. H. (2008). Positivist analysis on effect of monetary policy on stock price behaviors. In Proceedings of 2008 conference on regional economy and sustainable development, 679-687.

48. Smirlock, M. Yawitz, J. (1985). Asset returns, discount rate changes, and market efficiency. The Journal of Finance, 40, 1141-1158

49. Soureh, M.F. Hassanzadeh, B. R. Nahidi, M. (2014). the study of the effect of monetary policies on Iran's stock market bubble, Indian Journal of Fundamental and Applied Life Sciences, 4 (S3), 83-94.

50. Shukur, G. Mantalos, P.(1997a). Size and power of the RESET test as applied to systems of equations: a bootstrap approach. Working paper, Department of Statistics, University of Lund, Sweden.

51. Shukur, G. Mantalos, P. (1997b). Tests for Granger causality in integrated-cointegrated VAR systems. Working paper, Department of Statistics, University of Lund, Sweden.

52. Shukur, G. Mantalos, P. (2000). A simple investigation of the Granger-causality test in integratedcointegrated VAR Systems. Journal of Applied Statistics, 27, 1021-1031

53. Saleem, F. Zafar, L. Rafique, B. (2013). Long run relationship between inflation and stock return: evidence from Pakistan. Academic Research International, 4, 407-415.

54. Toda, H. Y. Phillips, P. C. B. (1994), Vector autoregression and causality: a theoretical overview and simulation study. Econometric Reviews, 13, 259-285;

Thorbecke, M. (1995). On Stock Market Returns and Monetary Policy. The Journal of Finance, 52, 2, 635654.

55. Zeileis A, Leisch F, Hornik K, Kleiber C. (2005). Monitoring structural change in dynamic econometric models. Journal of Applied Econometrics, 20, 99-121. 